\title{
Correction to: Total nephroureterocystectomy and urethrectomy due to urothelial carcinoma associated with the BK polyomavirus infection after kidney transplantation: a case report with literature review
}

Ryoichi Maenosono ${ }^{1,5}$, Masayoshi Okumi ${ }^{1}$, Kohei Unagami ${ }^{2,3 *}$, Hironori Fukuda ${ }^{1}$, Kazuhiko Yoshida', Yoichi Kakuta ${ }^{1}$, Toshio Takagi', Junpei lizuka', Tomokazu Shimizu', Haruhito Azuma ${ }^{5}$, Yoji Nagashima ${ }^{4}$ Kazunari Tanabe ${ }^{1}$, Kosaku Nitta ${ }^{2}$ and Hideki Ishida ${ }^{3}$

Correction to: Renal Replacement Therapy 6, 52 (2020) https://doi.org/10.1186/s41100-020-00297-6

The original article [1] contains errors in each author's institutional affiliations. The correct affiliations can be viewed in this Correction article.

\footnotetext{
Author details

'Urology, Kidney Center, Tokyo Women's Medical University, Tokyo, Japan. ${ }^{2}$ Nephrology, Kidney Center, Tokyo Women's Medical University, Tokyo, Japan. ${ }^{3}$ Departments of Organ Transplant, Tokyo Women's Medical University, 8-1 Kawada-cho, Shinjuku-ku, Tokyo 162-8666, Japan. ${ }^{4}$ Surgical Pathology, Tokyo Woman's Medical University, Tokyo, Japan. ${ }^{5}$ Department of Urology, Osaka Medical College, Osaka, Japan.
}

Published online: 16 December 2020

\section{Reference}

1. Maenosono R, et al. Total nephroureterocystectomy and urethrectomy due to urothelial carcinoma associated with the BK polyomavirus infection after kidney transplantation: a case report with literature review. Ren Replace Ther. 2020;6:52 https://doi.org/10.1186/s41100-020-00297-6.

The original article can be found online at https://doi.org/10.1186/s41100020-00297-6.

* Correspondence: unagami.kohei@twmu.ac.jp

${ }^{2}$ Nephrology, Kidney Center, Tokyo Women's Medical University, Tokyo, Japan

${ }^{3}$ Departments of Organ Transplant, Tokyo Women's Medical University, 8-1 Kawada-cho, Shinjuku-ku, Tokyo 162-8666, Japan

Full list of author information is available at the end of the article

(c) The Author(s). 2020 Open Access This article is licensed under a Creative Commons Attribution 4.0 International License, which permits use, sharing, adaptation, distribution and reproduction in any medium or format, as long as you give appropriate credit to the original author(s) and the source, provide a link to the Creative Commons licence, and indicate if changes were made. The images or other third party material in this article are included in the article's Creative Commons licence, unless indicated otherwise in a credit line to the material. If material is not included in the article's Creative Commons licence and your intended use is not permitted by statutory regulation or exceeds the permitted use, you will need to obtain permission directly from the copyright holder. To view a copy of this licence, visit http://creativecommons.org/licenses/by/4.0/ The Creative Commons Public Domain Dedication waiver (http://creativecommons.org/publicdomain/zero/1.0/) applies to the data made available in this article, unless otherwise stated in a credit line to the data. 